\section{International Organisation of La Francophonie}

The International Organisation of La Francophonie represents 77 countries and provinces/regions (including 20 with observer status) using French as an official language. It estimates that there are $220 \mathrm{~m}$. French speakers worldwide. Objectives include the promotion of peace, democracy, and economic and social development, through political and technical co-operation. The Secretary-General is based in Paris.

Members. Albania, Andorra, Armenia, Belgium, Benin, Bulgaria, Burkina Faso, Burundi, Cabo Verde, Cambodia, Cameroon, Canada, Canada-New Brunswick, Canada-Quebec, Central African Republic, Chad, Comoros, Democratic Republic of the Congo, Republic of the Congo, Côte d'Ivoire, Djibouti, Dominica, Egypt, Equatorial Guinea, France, French Community of Belgium, Gabon, Greece, Guinea, Guinea-Bissau, Haiti, Laos, Lebanon, Luxembourg, Macedonia, Madagascar, Mali, Mauritania, Mauritius, Moldova, Monaco, Morocco, Niger, Romania, Rwanda, St Lucia, São Tomé e Príncipe, Senegal, Seychelles, Switzerland, Togo, Tunisia, Vanuatu, Vietnam. Associate Members. Cyprus, Ghana, Qatar. Observers. Austria, Bosnia and Herzegovina, Croatia, Czech Republic, Dominican Republic, Estonia, Georgia, Hungary, Latvia, Lithuania, Montenegro, Mozambique, Poland, Serbia, Slovakia, Slovenia, Thailand, Ukraine, United Arab Emirates, Uruguay.

Headquarters: 19-21 avenue Bosquet, 75007 Paris, France. Website (limited English): http://www.francophonie.org Secretary-General: Michaëlle Jean (Haiti).

\section{International Organization for Migration (IOM)}

Established in 1951, the International Organization for Migration (IOM) is the principal intergovernmental organization in the field of migration.

Members (157 as of Feb. 2015). Afghanistan, Albania, Algeria, Angola, Antigua and Barbuda, Argentina, Armenia, Australia, Austria, Azerbaijan, Bahamas, Bangladesh, Belarus, Belgium, Belize, Benin, Bolivia, Bosnia and Herzegovina, Botswana, Brazil, Bulgaria, Burkina Faso, Burundi, Cabo Verde, Cambodia, Cameroon, Canada, Central African Republic, Chad, Chile, Colombia, Comoros, Democratic Republic of the Congo, Republic of the Congo, Costa Rica, Côte d'Ivoire, Croatia, Cyprus, Czech Republic, Denmark, Djibouti, Dominican Republic, Ecuador, Egypt, El Salvador, Estonia, Ethiopia, Fiji Islands, Finland, France, Gabon, Gambia, Georgia, Germany, Ghana, Greece, Guatemala, Guinea, Guinea-Bissau, Guyana, Haiti, Holy See, Honduras, Hungary, Iceland, India, Iran, Ireland, Israel, Italy, Jamaica, Japan, Jordan, Kazakhstan, Kenya, South Korea, Kyrgyzstan, Latvia, Lesotho, Liberia, Libya, Lithuania, Luxembourg, Macedonia, Madagascar, Malawii, Maldives, Mali, Malta, Marshall Islands, Mauritania, Mauritius, Mexico, Micronesia, Moldova, Mongolia, Montenegro, Morocco, Mozambique, Myanmar, Namibia, Nauru, Nepal, Netherlands, New Zealand, Nicaragua, Niger, Nigeria, Norway, Pakistan, Panama, Papua New Guinea, Paraguay, Peru, Philippines, Poland, Portugal, Romania, Rwanda, St Vincent and the Grenadines, Samoa, Senegal, Serbia, Seychelles, Sierra Leone, Slovakia, Slovenia, Somalia, South Africa, South Sudan, Spain, Sri Lanka, Sudan, Suriname, Swaziland, Sweden, Switzerland, Tajikistan, United Republic of Tanzania, Thailand, Timor-Leste, Togo, Trinidad and Tobago, Tunisia, Turkey, Turkmenistan,
Uganda, Ukraine, UK, USA, Uruguay, Vanuatu, Venezuela, Vietnam, Yemen, Zambia and Zimbabwe. A further ten countries have observer status.

Activities. IOM works to help ensure the orderly and humane management of migration, to promote international co-operation on migration issues, to assist in the search for practical solutions to migration problems and to provide humanitarian assistance to migrants in need, be they refugees, displaced persons or other uprooted people. The IOM Constitution gives explicit recognition to the link between migration and economic, social and cultural development, as well as to the right of freedom of movement of persons. IOM's programme budget for 2012 exceeded US $\$ 1 \cdot 2 \mathrm{bn}$., funding over 2,300 active programmes and more than 7,800 staff members serving in over 470 field offices in more than 100 countries.

Official languages: English, French, Spanish.

Headquarters: Route des Morillons 17, POB 71,

CH-1211 Geneva 19, Switzerland.

Website: http://www.iom.int

Director-General: William Lacy Swing (USA).

\section{International Organization for Standardization (ISO)}

Established in 1947, the International Organization for Standardization is a non-governmental federation of national standards bodies from 161 countries worldwide, one from each country. ISO's work results in international agreements which are published as International Standards. The first ISO standard was published in 1951 with the title 'Standard reference temperature for industrial length measurement'.

Some 19,500 ISO International Standards are available on subjects in such diverse fields as information technology, textiles, packaging, distribution of goods, energy production and utilization, building, banking and financial services. ISO standardization activities include the widely recognized ISO 9000 family of quality management system and standards and the ISO 14000 series of environmental management system standards. Standardization programmes are now being developed in completely new fields, such as food safety, security, social responsibility and the service sector.

Mission. To promote the development of standardization and related activities in the world with a view to facilitating the international exchange of goods and services, and to developing co-operation in the spheres of intellectual, scientific, technological and economic activity.

Headquarters: 1 chemin de la Voie-Creuse, Case postale 56,

CH-1211 Geneva 20, Switzerland.

Website: http://www.iso.org

Secretary-General: Rob Steele (New Zealand).

\section{International Road Federation (IRF)}

The IRF is a non-profit, non-political service organization whose purpose is to encourage better road and transportation systems worldwide and to help apply technology and management practices to give maximum economic and social returns from national road investments. 